\title{
Laboratory Evaluation of Three Rapid, Agar-Based Assays to Assess Fungicide Sensitivity in Monilinia fructicola
}

\author{
A. Amiri, Department of Entomology, Soils, and Plant Sciences, Clemson University, Clemson, SC 29634; \\ H. Scherm and P. M. Brannen, Department of Plant Pathology, University of Georgia, Athens 30602; and \\ G. Schnabel, Department of Entomology, Soils, and Plant Sciences, Clemson University
}

\begin{abstract}
Amiri, A., Scherm, H., Brannen, P. M., and Schnabel, G. 2008. Laboratory evaluation of three rapid, agar-based assays to assess fungicide sensitivity in Monilinia fructicola. Plant Dis. 92:415-420.

Three rapid, agar-based assays were compared with a traditional petri dish method for assessing the sensitivity of Monilinia fructicola to propiconazole $(0.3$ and $2.0 \mu \mathrm{g} / \mathrm{ml})$, thiophanate-methyl $(1.0$ and $50 \mu \mathrm{g} / \mathrm{ml})$, and azoxystrobin $(1.0$ and $35 \mu \mathrm{g} / \mathrm{ml})$ in the laboratory. The three assays were based on mycelial growth inhibition on agar disks sliced from lipbalm tubes filled with fungicide-amended potato dextrose agar (PDA), on PDA-coated cotton swabs, or in PDA-filled microcentrifuge tubes. Mycelial growth inhibition of eight previously characterized isolates (two resistant to propiconazole, two highly resistant to thiophanate-methyl, two with low levels of resistance to thiophanate-methyl, and two sensitive to all three fungicides) was determined visually 24,48 , and $72 \mathrm{~h}$ after inoculation. The 48 -h time point was the earliest suitable time to collect data for all methods because insufficient growth was recorded in the petri dish and tube assays after $24 \mathrm{~h}$. With the exception of the swab assay, all methods classified the isolates previously determined to be fungicide sensitive correctly (i.e., no fungal growth was observed for these isolates). For propiconazole-resistant isolates, the lipbalm assay resulted in levels of growth inhibition very similar to the petri dish method, whereas the swab assay and the tube assay overestimated and underestimated, respectively, the level of resistance. Both the lipbalm and the swab assays classified isolates correctly as being thiophanate-methyl resistant, and both were able to discriminate the isolates previously classified as having low versus high levels of resistance when treated with this fungicide at $50 \mu \mathrm{g} / \mathrm{ml}$, as was the petri dish method. None of the eight isolates which previously were determined to be azoxystrobin sensitive grew on azoxystrobin-amended media, regardless of the assay type. Overall, the average percentage of correct isolate classifications (relative to their previously determined resistance status) on propiconazole- and thiophanate-methyl-amended media after $48 \mathrm{~h}$ ranged from 87.5 to $100,85.3$ to 100 , 63.2 to 94.5 , and 50.5 to $81.0 \%$ for the petri dish, lipbalm, swab, and tube assays, respectively. The lipbalm assay provided the most accurate assessments (85.3 to 100\%) after only $24 \mathrm{~h}$ of incubation, supporting its use as a rapid and simple tool to monitor resistance levels in M. fructicola field populations.
\end{abstract}

Additional keywords: benzimidazole, brown rot, demethylation inhibitor, quinone outside inhibitor

Monilinia fructicola can infect flowers, shoots, and fruit of stone fruits (Prunus spp.), causing blossom blight, twig canker, and brown rot, respectively (18). Of these symptom types, preharvest brown rot is the most economically important. The strategy used currently to control brown rot includes sanitation practices, cultural methods, and chemical control measures (5). Given the explosive nature of preharvest brown rot epidemics, management is most dependent on repeated fungicide applications in the final 2 to 3 weeks before harvest.

Corresponding author: G. Schnabel

E-mail: schnabe@clemson.edu

Accepted for publication 7 October 2007.

doi:10.1094/PDIS-92-3-0415

() 2008 The American Phytopathological Society
Following reports of resistance development in populations of M. fructicola to the widely used benzimidazole (BZI) fungicides $(19,26)$, the demethylation inhibitors (DMIs), especially propiconazole, replaced the BZIs as the mainstay of preharvest brown rot control during the 1980s. For more than two decades, DMI fungicides have been used almost exclusively in the southeastern United States and elsewhere to control brown rot without indication of resistance development. However, evidence for brown rot control failures despite DMI applications began to accumulate in the main peach-production areas of Georgia in 2002. Subsequently, isolates from this region were shown to be less sensitive to propiconazole and caused disease on inoculated peach fruit treated with labeled rates of a commercial propiconazole formulation (23). Since then, brown rot control failures following application of propiconazole have occurred in replicated field trials in Georgia (4), and M. fructicola isolates resistant to DMI fungicides have been reported from other peachproduction areas in the United States (20).

In the past few years, fungicides with alternative modes of action have been labeled for brown rot control, including the quinone outside inhibitors (QoIs) azoxystrobin and pyraclostrobin. These active ingredients are single-site inhibitors and, as such, they are at high risk of resistance development. Indeed, resistance to QoI fungicides has been reported in a number of pathosystems $(11,15,21)$, including fungal pathogens of perennial crops such as apple (12) and grape (10).

With the recent advent of reduced sensitivity to DMI fungicides in populations of the brown rot fungus in Georgia and elsewhere, resistance management has taken on a new urgency. To what degree BZI resistance is still present in $M$. fructicola populations in the southeastern United States is currently unknown. Resistance to QoI fungicides has not been reported in the peach brown rot pathosystem; however, the absence of viable alternatives likely will result in increased use of QoIs, with associated increase in selection pressure for resistance. Given this scenario, simple technologies need to be developed to determine the resistance profile in orchard populations of $M$. fructicola toward the three key fungicide groups for preharvest brown rot management. Such methodologies should be able to determine the geographical extent of DMI and QoI resistance and the occurrence of residual resistance to BZIs which have seen very limited use for many years in the southeast.

Traditionally, petri dish assays have been used to determine fungicide resistance in populations of fungal plant pathogens $(1,2)$. These methods are time consuming (they often involve a 7- to 14-day incubation period) and require large amounts of prepared agar media. A more time-saving method has been developed recently using a spiral plater for more rapid determination of resistance levels; however, this technique still requires single-spore isolations and comparably expensive equipment (8). Furthermore, these methods are unsuitable for field use and do not provide near-real-time information. Polymerase chain reaction (PCR) or realtime PCR-based approaches have been 
used extensively for resistance monitoring in fungal populations $(9,14,16)$. Again, these methods, although providing very rapid turnaround times, generally are un-

The objective of this study was to develop and validate a simple and rapid assay suitable for future in-field use to assess fungicide sensitivity in $M$. fructicola populations. The focus was on assays that are agar based (thus ensuring wide availability), miniaturized (ensuring portability and low cost), and allow visual assessment of the results within a 1- to 3-day incubation period.

\section{MATERIALS AND METHODS}

Fungal isolates and inoculum production. Eight previously characterized isolates of M. fructicola with different levels of sensitivity to DMI, BZI, and QoI fungicides were used in this study (Table 1). Isolates were classified as sensitive or resistant to the DMI propiconazole when the effective concentrations of fungicide that inhibited fungal growth by $50 \%\left(\mathrm{EC}_{50}\right.$ values) were $<0.02$ and $>0.3 \mu \mathrm{g} / \mathrm{ml}$, respectively (23). Isolates were classified as sensitive, having a low resistance level, or being highly resistant to the BZI thiophanate-methyl when $\mathrm{EC}_{50}$ values were $<0.7$, 2.0 to 6.0 , or $>50 \mu \mathrm{g} / \mathrm{ml}$, respectively (17). Isolates of $M$. fructicola resistant to QoI fungicides have not been reported at the time of this study, and the eight isolates used in this investigation have not been exposed to QoI fungicides in the field; therefore, they were considered sensitive to QoI fungicides. Their $\mathrm{EC}_{50}$ values for azoxystrobin were $<0.5 \mu \mathrm{g} / \mathrm{ml}$. In this article, a superscript indicating resistance was added to the isolate designation for all fungicide-resistant isolates; if an isolate was not resistant to any of the fungicides, no superscript was added.

All isolates were stored at $-80^{\circ} \mathrm{C}$ on silica gel (grade 40; Sigma-Aldrich, St. Louis, MO). Conidia were produced on cling stone peach halves in pear juice (Great Value brand; Wal-Mart, Bentonville, AR), which were placed round side up in sterile Magenta tissue culture boxes. Each peach half was inoculated with two plugs from the margins of a 7-day-old colony suitable for on-farm use.

growing on potato dextrose agar (PDA) and then incubated at $22^{\circ} \mathrm{C}$ for 6 to 7 days. Conidia produced in this manner were used in the assay evaluation experiments described below. For each of the two independent experiments, new cultures were started from silica gel stock.

Experimental fungicides and discriminatory doses. All fungicides used in this study were formulated, commercial products. Propiconazole (Orbit; Syngenta Crop Protection, Greensboro, NC) was used at 0.3 and $2.0 \mu \mathrm{g} / \mathrm{ml}$. The discriminatory dose of $0.3 \mu \mathrm{g} / \mathrm{ml}$ was shown previously to distinguish between baseline (sensitive) and resistant populations of $M$. fructicola (23), and the $2.0 \mu \mathrm{g} / \mathrm{ml}$ dose was added to identify highly resistant isolates. Thiophanate-methyl (Topsin-M WSB; Ceraxagri, King of Prussia, PA) was tested at concentrations of 1.0 and $50 \mu \mathrm{g} / \mathrm{ml}$ as described previously (17) to determine low (LR) and high (HR) levels of BZI resistance, respectively. Based on the $\mathrm{EC}_{50}$ values of azoxystrobin-resistant isolates of other plant-pathogenic Ascomycetes, which range from 1.2 to $44.7 \mu \mathrm{g} / \mathrm{ml}(3,11)$, we chose azoxystrobin (Abound; Syngenta) at 1.0 and $35 \mu \mathrm{g} / \mathrm{ml}$ to screen for low and high levels of resistance, respectively. Salicylhydroxamic acid (SHAM) was dissolved in ethanol and added at a concentration of $100 \mu \mathrm{g} / \mathrm{ml}$ to azoxystrobin-amended media to suppress the alternative oxidase pathway (25). At this concentration, SHAM does not directly impact spore germination or mycelial growth of $M$. fructicola (24). All fungicides were added to autoclaved PDA medium cooled to $50^{\circ} \mathrm{C}$ and amended with streptomycin at $1.0 \mu \mathrm{g} / \mathrm{ml}$.

Fungicide sensitivity assays. Three rapid, agar-based assays were compared with a petri dish method $(1,2)$ to evaluate the sensitivity of $M$. fructicola isolates to the three fungicides. Two independent experiments were conducted, each with five replicates of each assay-isolatefungicide concentration combination.

Lipbalm assay. Standard-sized lipbalm tubes $(15 \mathrm{~mm}$ in diameter, $60 \mathrm{~mm}$ long; SKS, Watervliet, NY) were autoclaved and filled with unamended or fungicideamended molten PDA (Fig. 1A). After the

Table 1. Characteristics of Monilinia fructicola isolates used in this study

\begin{tabular}{lcccccc}
\hline & & & & \multicolumn{2}{c}{$\begin{array}{c}\text { Fungicide sensitivity } \\
\text { classification }\end{array}$} \\
\cline { 5 - 7 } Isolate & Geographic origin & Year isolated & Host & DMI & BZI & QoI \\
\hline 99.O3 & Edgefield, SC & 2004 & Peach & $\mathrm{S}$ & $\mathrm{S}$ & $\mathrm{S}$ \\
99.A3 & Edgefield, SC & 2004 & Peach & $\mathrm{S}$ & $\mathrm{S}$ & $\mathrm{S}$ \\
DL133 & Fort Valley, GA & 2004 & Peach & $\mathrm{R}$ & $\mathrm{S}$ & $\mathrm{S}$ \\
Bmpc9 & Fort Valley, GA & 2006 & Peach & $\mathrm{R}$ & $\mathrm{S}$ & $\mathrm{S}$ \\
ms15 & Madera, CA & 2002 & Peach & $\mathrm{S}$ & $\mathrm{LR}$ & $\mathrm{S}$ \\
33L7 & Fresno, CA & 1998 & Plum & $\mathrm{S}$ & $\mathrm{LR}$ & $\mathrm{S}$ \\
139 & Fresno, CA & 2005 & Peach & $\mathrm{S}$ & $\mathrm{HR}$ & $\mathrm{S}$ \\
190 & Fresno, CA & 2005 & Peach & $\mathrm{S}$ & $\mathrm{HR}$ & $\mathrm{S}$
\end{tabular}

${ }^{a} \mathrm{DMI}=$ demethylation inhibitor, $\mathrm{BZI}=$ benzimidazole, $\mathrm{QoI}=$ quinone outside inhibitor, $\mathrm{S}=$ sensitive, $\mathrm{R}=$ resistant, $\mathrm{LR}=$ low resistance level, and $\mathrm{HR}=$ high resistance level. medium had solidified, tubes were capped and stored at $4^{\circ} \mathrm{C}$ for no longer than 2 weeks before use. Tubes contained a threaded shaft ( $3 \mathrm{~mm}$ in diameter) in the center that stretched from the base to the top of the tube, allowing the movement of the PDA core by turning the base clockwise. As the base was turned, disks (approximately $3 \mathrm{~mm}$ thick) containing a 3 $\mathrm{mm}$ hole in the center from the threaded shaft were sliced from the PDA core with a sterile scalpel. Five disks per isolate, fungicide concentration, and experimental run were placed into an empty $50-\mathrm{mm}$ petri dish (Fig. 1B) and inoculated with conidia produced on peach halves. Conidia from each isolate grown on a peach half were collected by swirling a cotton tip of a sterile swab applicator (Puritan, Guilford, ME) in the sporulating area of the peach half and subsequently swirled around the inner edge of each disk (Fig. 1C). After inoculation, the petri dishes were covered with a lid, sealed with Parafilm, and incubated at $22^{\circ} \mathrm{C}$ for $72 \mathrm{~h}$. Mycelial growth (Fig. 1D) was measured daily with the unaided eye using a digital caliper.

Swab assay. The tips of sterile cotton swabs (70 $\mathrm{mm}$ long and $3 \mathrm{~mm}$ in diameter; Johnson \& Johnson, Skillman, NJ) were coated by dipping $2 \mathrm{~cm}$ of the swab in a $0.5-\mathrm{ml}$ centrifuge tube containing $0.4 \mathrm{ml}$ of unamended or fungicide-amended molten PDA (Fig. 1E). The devices were stored in sterile 5-ml polystyrene tubes equipped with rubber caps (Falcon, Becton Dickinson Labware, Franklin Lakes, NJ). The part of the swab opposite to the cotton tip was squeezed through a hole in the cap made with a sterile needle (Fig. 1F). The tubes containing the PDA-coated swabs were stored at $4{ }^{\circ} \mathrm{C}$ for up to 2 weeks before use. Swabs were inoculated by touching the sporulating area of a peach half with the PDA-coated tip (Fig. 1G). The swab was returned immediately to the polystyrene tube and incubated "standing up." To increase humidity, 200 $\mu \mathrm{l}$ of sterile distilled water was added to each tube without moistening the PDA. Five swabs were inoculated for each isolate, fungicide concentration, and experimental run. Mycelial growth along the tip (Fig. 1H) was measured as described above.

Tube assay. Translucent $0.5-\mathrm{ml}$ microcentrifuge tubes (USA Scientific, Ocala, FL) were filled with $0.4 \mathrm{ml}$ of unamended or fungicide-amended molten PDA (Fig. 1I) and stored at $4^{\circ} \mathrm{C}$ until further use. The medium was inoculated by touching the sporulating area of a peach half with the inner face of the cap (Fig. 1J) and bringing the conidia in contact with the medium surface by snapping the cap onto the tube (Fig. 1K). Five tubes were inoculated for each isolate, fungicide concentration, and experimental run. Mycelial growth along the tube (Fig. 1L) was determined as described above. 
Petri dish method. This method was conducted as described previously (25). Unamended or fungicide-amended PDA $(30 \mathrm{ml})$ was poured into plastic petri dishes (90 $\mathrm{mm}$ in diameter) and dishes were stored at $4^{\circ} \mathrm{C}$ for up to 2 weeks before use. Dishes were inoculated by placing a PDA plug ( $5 \mathrm{~mm}$ in diameter), taken from the periphery of a 3-day-old culture, upside down in the center of the dish. Colony diameter was measured as described above at only one point when regular mycelial growth was observed. In case of irregular mycelial growth, two perpendicular measurements were made and an average of the two values was calculated.
Data analysis. Each assay was tested with the eight isolates and the two concentrations of each active ingredient. Results from the two experimental runs were similar; therefore, data were combined for analysis. Qualitative data consisted of visual records of the presence or absence of mycelial growth after 24, 48, and $72 \mathrm{~h}$, whereas quantitative information consisted of mycelial growth measurements (in millimeters) at the same time points. Presence-or-absence data were used to calculate the accuracy of each method (i.e., the percentage of correct observations). A correct observation was defined as the expected presence or absence of mycelial growth depending on the previously determined isolate characteristic. For example, if isolate DL133 ${ }^{\text {DMI-R }}$ grew on propiconazole-amended medium, the observation was rated "correct" because this isolate was expected to be resistant to DMI fungicides. In contrast, if DL133 $3^{\text {DMI-R }}$ grew on thiophanate-methyl-amended medium, the observation was considered "incorrect."

Data on mycelial growth were used to compute growth inhibition (percentage) in relation to the unamended control. Based on the five replicates and two experimental runs for each combination of isolate, means and $95 \%$ confidence intervals (CIs) were computed for statistical evaluation

\section{Lipbalm tube assay}
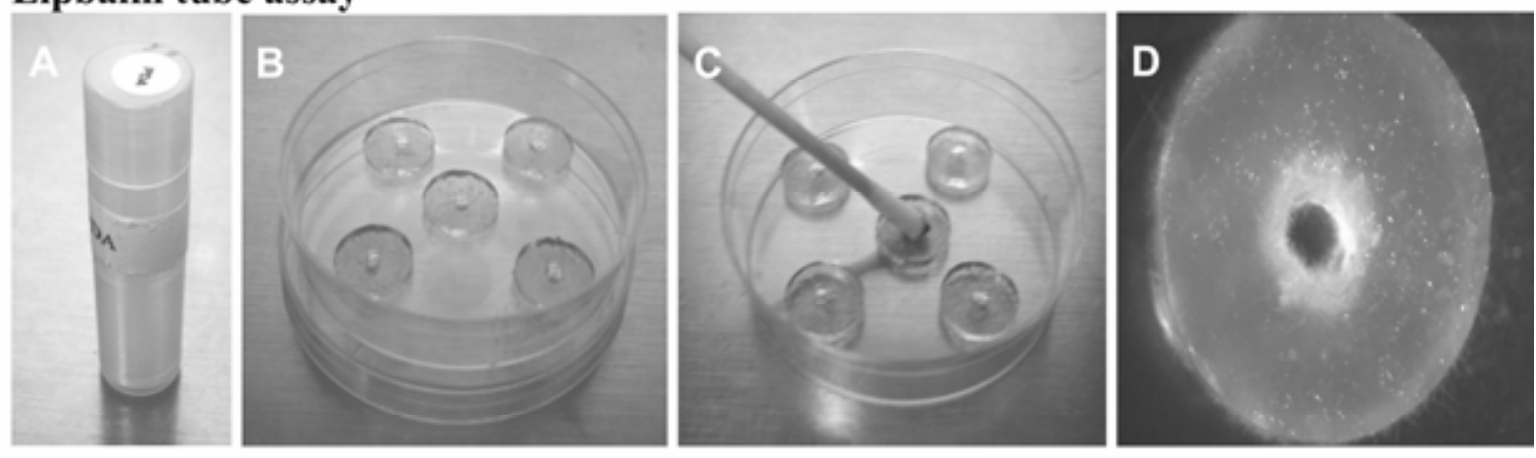

\section{Swab assay}
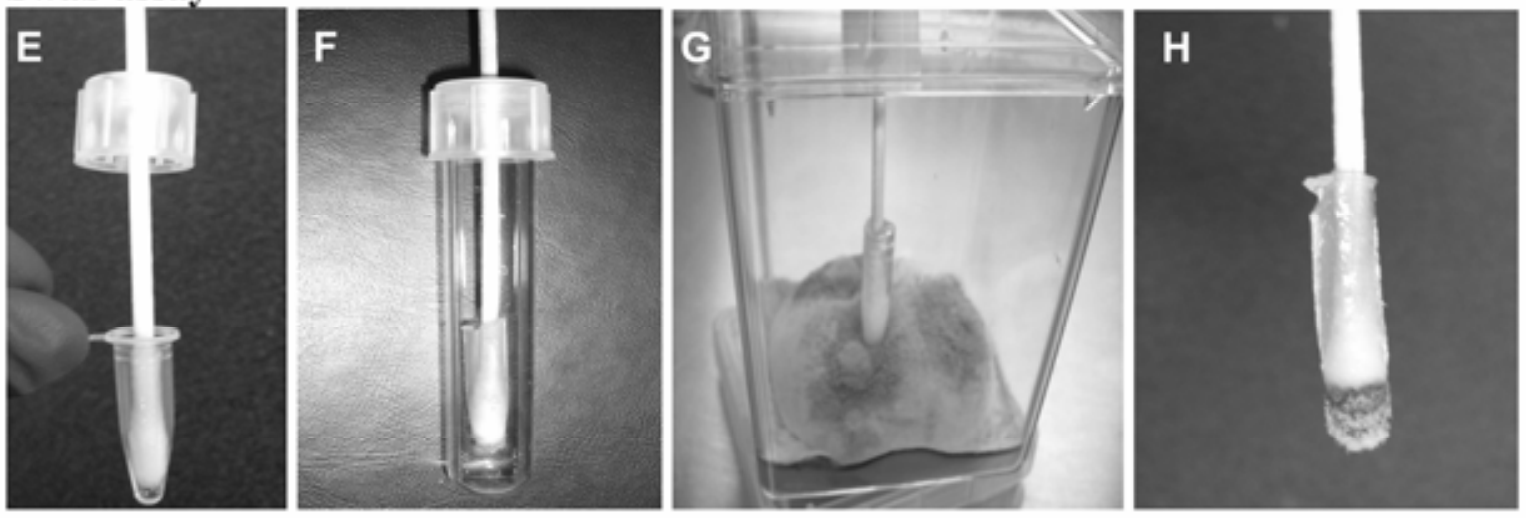

\section{Tube assay}
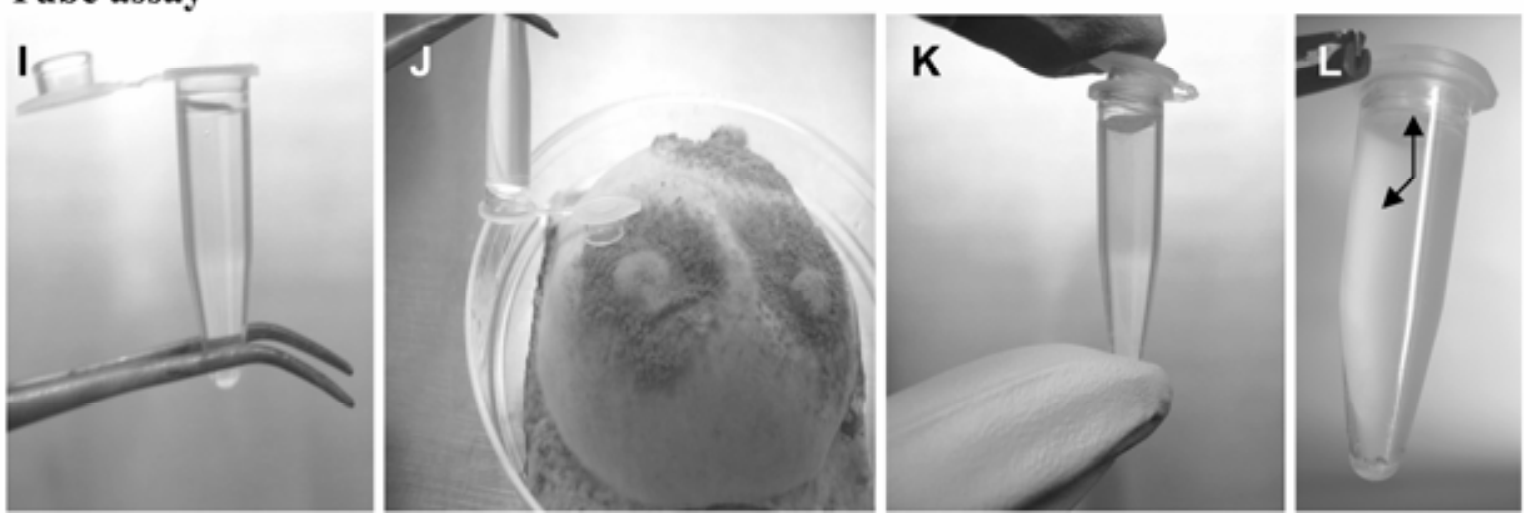

Fig. 1. Illustration of lipbalm, swab, and tube assays used to assess fungicide sensitivity in Monilinia fructicola. A, Lipbalm tube filled with potato dextrose agar (PDA); $\mathbf{B}$, sliced agar disks in petri dish; $\mathbf{C}$, inoculation of disks with conidia using a sterile applicator; $\mathbf{D}$, mycelial growth starting from inner edge of disk; E, cotton swab dipped in liquid PDA and stored in polystyrene tube; $\mathbf{F}$, until being inoculated; $\mathbf{G}$ and $\mathbf{H}$, mycelial growth along PDA core; $\mathbf{I}$, microcentrifuge tube filled with $0.4 \mathrm{ml}$ of PDA; $\mathbf{J}$, inner face of cap applied against sporulating area of peach fruit; $\mathbf{K}$, inoculation of agar by closing cap; $\mathbf{L}$, mycelial growth on agar surface and along the tube (as indicated by arrows). 
(6). No formal hypothesis tests were carried out due to violation of the underlying assumptions (i.e., numerous treatments with $100 \%$ growth inhibition and associated zero variance).

\section{RESULTS}

Inhibition of mycelial growth. After 24 $h$ of incubation, no mycelial growth was observed in the tube and petri dish assays, even for the unamended medium. On the other hand, mycelial growth values after $72 \mathrm{~h}$ of incubation (data not shown) were very similar to those obtained after $48 \mathrm{~h}$. Therefore, only data collected after $48 \mathrm{~h}$ of incubation are presented for this response variable.

When the eight isolates were subjected to the two doses of propiconazole, results were equivalent for the petri dish and lipbalm assays (i.e., the two assays had very similar mean values of mycelial growth inhibition and overlapping CIs; Table 2). With both assays, the six isolates previously designated DMI sensitive showed $100 \%$ inhibition, whereas the two DMIresistant isolates showed incomplete inhibition with propiconazole at $0.3 \mu \mathrm{g} / \mathrm{ml}$. Relative to these two assays, there was less inhibition (for five and two of the eight isolates at 0.3 and $2.0 \mu \mathrm{g} / \mathrm{ml}$, respectively) in the swab assay. In contrast, mycelial growth was inhibited completely (even for the DMI-resistant isolates) in the tube assay (Table 2).

When the two doses of thiophanatemethyl were evaluated, all four isolates previously designated BZI sensitive showed $100 \%$ growth inhibition in the petri dish, lipbalm, and tube assays (Table 3). In contrast, three of these four sensitive isolates showed incomplete inhibition with thiophanate-methyl at $1.0 \mu \mathrm{g} / \mathrm{ml}$ when evaluated in the swab assay. For the isolates designated BZI-resistant, results were inconsistent for the petri dish assay with thiophanate-methyl at $1.0 \mu \mathrm{g} / \mathrm{ml}$; however, the tests at $50 \mu \mathrm{g} / \mathrm{ml}$ readily distinguished between BZI-LR and BZI-HR isolates (Table 3). At that concentration, the separation between these two isolate groups was less clear in the lipbalm and swab assays, although BZI-HR isolates did grow better on average than BZI-LR isolates. In contrast, the tube assay was unable to identify the BZI-resistant isolates consistently.

An example of mycelial growth on inoculated lipbalm disks unamended or amended with thiophanate-methyl at the two different doses is provided in Figure 2. The images show colonization starting from the inoculated inner edge of the disks.

Both the low $(1.0 \mu \mathrm{g} / \mathrm{ml})$ and high $(35$ $\mu \mathrm{g} / \mathrm{ml}$ ) doses of azoxystrobin inhibited mycelial growth completely with all four assays and for all isolates (data not shown).

Assay accuracy. In general, more correct observations (i.e., sensitive isolates classified as sensitive and resistant isolates classified as resistant) were recorded when assessments were done 48 rather than $24 \mathrm{~h}$ after inoculation, except for the swab assay
(Table 4). After $24 \mathrm{~h}$, accuracy varied from 74.4 to $100 \%$ for the petri dish assay, 85.3 to $100 \%$ for the lipbalm assay, 63.5 to $94.5 \%$ for the swab assay, and 50.5 to $75 \%$ for the tube assay, depending on the fungicide and its concentration. The corresponding values after $48 \mathrm{~h}$ were 87.5 to 100 , 85.3 to $100,63.2$ to 86.5 , and 75 to $81.0 \%$, respectively. Thus, the lipbalm and the petri dish assays consistently had the largest number of correct observations across fungicides, fungicide doses, and evaluation times. In fact, in all cases, the very similar means and overlapping CIs showed no significant differences between these two assays.

\section{DISCUSSION}

The growth inhibition data from the lipbalm assay were consistent with the assessments obtained from the petri dish method for $M$. fructicola isolates with different fungicide resistance phenotypes. Both assays identified DMI sensitivity, DMI resistance, and QoI sensitivity equally well. Both assays also distinguished BZI-LR and BZI-HR isolates from sensitive isolates at both doses of thiophanate-methyl, as well as from each other at the high concentration of the BZI fungicide. After $48 \mathrm{~h}$ of incubation, the petri dish method did not always reflect the expected phenotype, as indicated by some accuracy data lower than $100 \%$. This was likely because, with this method, measurement of mycelial growth of slowgrowing isolates was difficult. The accu-

Table 2. Mycelial growth inhibition of Monilinia fructicola isolates in four assays involving media amended with two concentrations of propiconazole $48 \mathrm{~h}$ after inoculation

\begin{tabular}{|c|c|c|c|c|c|c|c|c|}
\hline \multirow[b]{3}{*}{ Isolate } & \multicolumn{8}{|c|}{ Mycelial growth inhibition $(\%)^{a}$} \\
\hline & \multicolumn{4}{|c|}{ Propiconazole at $0.3 \mu \mathrm{g} / \mathrm{ml}$} & \multicolumn{4}{|c|}{ Propiconazole at $2.0 \mu \mathrm{g} / \mathrm{ml}$} \\
\hline & Petri dish & Lipbalm & Swab & Tube & Petri dish & Lipbalm & Swab & Tube \\
\hline 99.03 & 100 & 100 & 100 & 100 & 100 & 100 & 100 & 100 \\
\hline 99.A3 & 100 & 100 & 100 & 100 & 100 & 100 & 100 & 100 \\
\hline DL133 $3^{\text {DMI-R }}$ & $75.0 \pm 14.8$ & $72.1 \pm 15.6$ & $38.0 \pm 11.5$ & 100 & 100 & 100 & $70.0 \pm 24.5$ & 100 \\
\hline Bmpc9 9 DMI-R & $71.0 \pm 13.6$ & $62.3 \pm 10.6$ & $39.0 \pm 13.2$ & 100 & 100 & 100 & $66.3 \pm 12.5$ & 100 \\
\hline $\mathrm{ms} 15^{\text {BZI-LR }}$ & 100 & 100 & 100 & 100 & 100 & 100 & 100 & 100 \\
\hline 33L $7^{\text {BZI-LR }}$ & 100 & 100 & $73.0 \pm 18.4$ & 100 & 100 & 100 & 100 & 100 \\
\hline $139^{\text {BZI-HR }}$ & 100 & 100 & $82.7 \pm 14.8$ & 100 & 100 & 100 & 100 & 100 \\
\hline $190^{\text {BZI-HR }}$ & 100 & 100 & $81.7 \pm 14.1$ & 100 & 100 & 100 & 100 & 100 \\
\hline
\end{tabular}

${ }^{\text {a }}$ Data are means $\pm 95 \%$ confidence intervals of 5 replicates per isolate across 2 experimental runs.

Table 3. Mycelial growth inhibition of Monilinia fructicola isolates in four assays involving media amended with two concentrations of thiophanate-methyl $48 \mathrm{~h}$ after inoculation

\begin{tabular}{|c|c|c|c|c|c|c|c|c|}
\hline \multirow[b]{3}{*}{ Isolate } & \multicolumn{8}{|c|}{ Mycelial growth inhibition $(\%)^{\mathrm{a}}$} \\
\hline & \multicolumn{4}{|c|}{ Thiophanate-methyl at $1.0 \mu \mathrm{g} / \mathrm{ml}$} & \multicolumn{4}{|c|}{ Thiophanate-methyl at $50.0 \mu \mathrm{g} / \mathrm{ml}$} \\
\hline & Petri dish & Lipbalm & Swab & Tube & Petri dish & Lipbalm & Swab & Tube \\
\hline 99.03 & 100 & 100 & $72.3 \pm 5.2$ & 100 & 100 & 100 & 100 & 100 \\
\hline 99.A3 & 100 & 100 & $56.3 \pm 21.0$ & 100 & 100 & 100 & 100 & 100 \\
\hline DL133 DMI-R & 100 & 100 & $61.7 \pm 12.2$ & 100 & 100 & 100 & 100 & 100 \\
\hline Bmpc $9^{\text {DMI-R }}$ & 100 & 100 & 100 & 100 & 100 & 100 & 100 & 100 \\
\hline $\mathrm{ms} 15^{\text {BZI-LR }}$ & $4.3 \pm 7.3$ & $38.8 \pm 20.9$ & $22.4 \pm 14.9$ & $73.9 \pm 10.1$ & $91.5 \pm 6.7$ & $77.7 \pm 18.9$ & $41.6 \pm 8.4$ & $90.6 \pm 9.5$ \\
\hline $33 \mathrm{~L} 7^{\text {BZI-LR }}$ & $52.5 \pm 14.1$ & $69.5 \pm 13.8$ & $72.2 \pm 8.6$ & 100 & $80.2 \pm 9.5$ & $50.0 \pm 37.7$ & $60.1 \pm 38.5$ & 100 \\
\hline $139^{\text {BZI-HR }}$ & $37.3 \pm 11.7$ & $46.0 \pm 20.8$ & $22.8 \pm 11.1$ & 100 & $34.8 \pm 10.9$ & $40.1 \pm 10.2$ & $12.3 \pm 7.3$ & $86.2 \pm 1.1$ \\
\hline $190^{\text {BZI-HR }}$ & $-4.8 \pm 2.3$ & $32.1 \pm 9.9$ & $43.1 \pm 16.6$ & 100 & $-49.0 \pm 7.1$ & $11.5 \pm 8.7$ & $33.0 \pm 6.9$ & 100 \\
\hline
\end{tabular}

${ }^{a}$ Data are means $\pm 95 \%$ confidence intervals of 5 replicates per isolate across 2 experimental runs. 
racy improved substantially (to 95\%) after $72 \mathrm{~h}$ of incubation (data not shown). Fungal growth inhibition observed in the swab and tube assays often differed from results of the petri dish and lipbalm assays, and the accuracy of the swab and tube assays was consistently lower. In addition, the use of the swab assay generally resulted in a higher frequency of contamination (data not shown).

The lipbalm device first was described in 1984 to sample and assay conidia of Venturia inaequalis in the field by pressing the water agar surface of the core against a sporulating lesion (13). This technique also was used later to monitor for BZI resistance in South Carolina peach orchards (26). However, as used in these studies, the method had important limitations. Because of the slow hyphal growth on water agar and the small diameter of the tubes used originally, the technique was restricted to assessing inhibition of conidial germination. In contrast, the modified assay developed here was based on a combination of conidial germination and mycelial growth inhibition by using lipbalm disks with a rich medium and larger diameter that allowed measurement of mycelial growth.

Collection of spores from sporulating lesions in the field using the lipbalm device is a nonsterile method that is prone to contamination, especially when using rich media such as PDA. In order to minimize potential contamination problems, we collected conidia from sporulating areas with a sterile cotton-tipped applicator and inoculated the inner edge of the disk instead of applying the entire agar core

\section{Control}
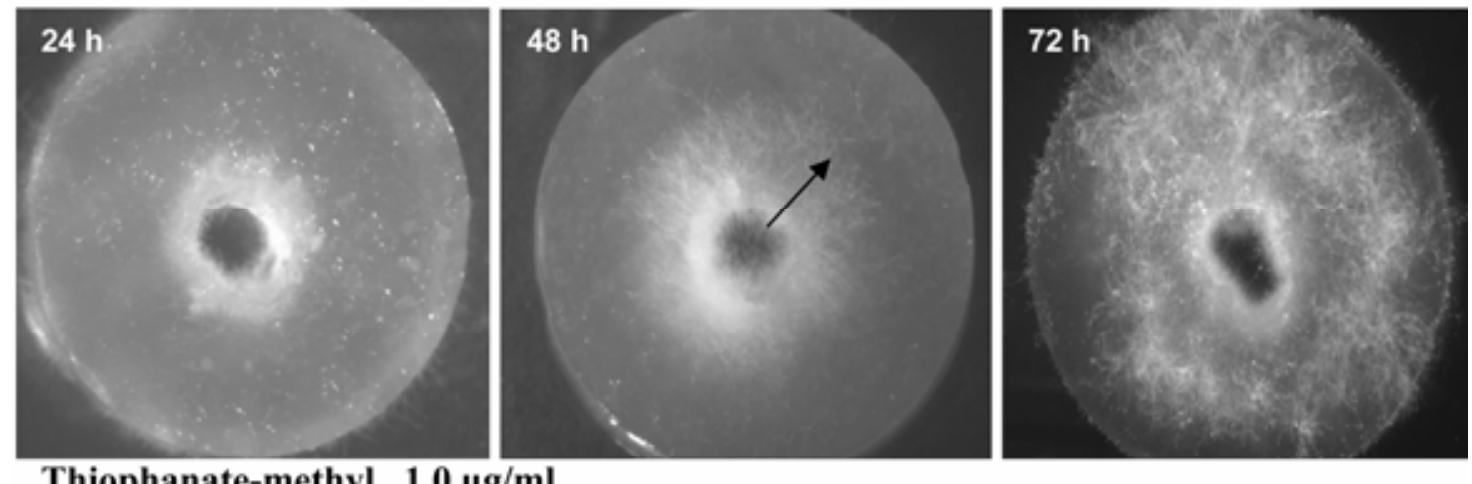

\section{Thiophanate-methyl $\quad 1.0 \mu \mathrm{g} / \mathrm{ml}$}
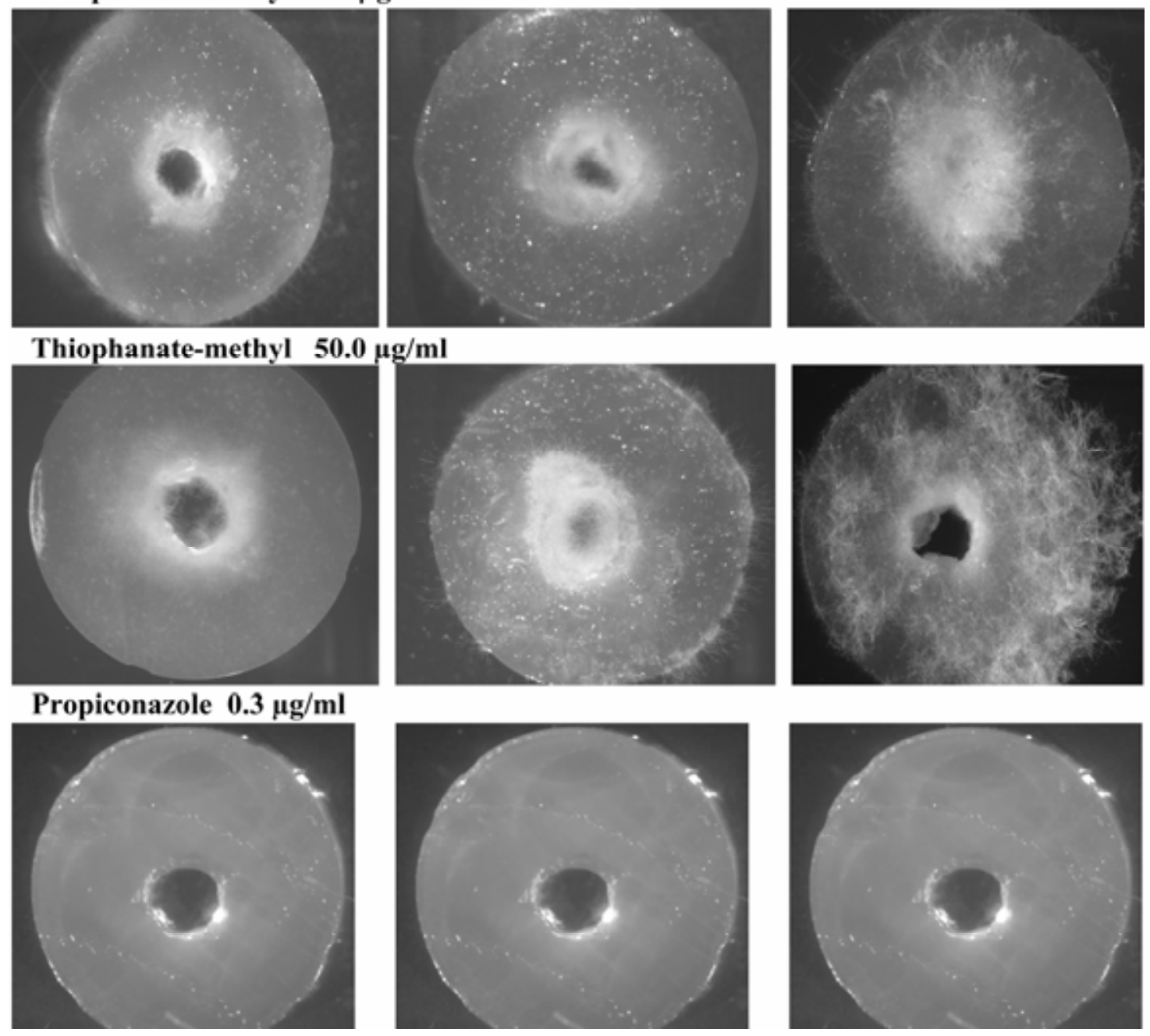

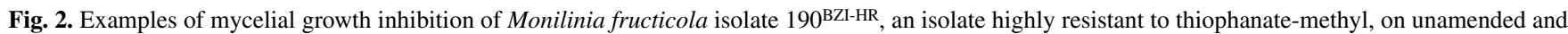
fungicide-amended lipbalm disks observed under a stereomicroscope $(\times 7.5)$ after 24,48 , and $72 \mathrm{~h}$ of incubation at $22^{\circ} \mathrm{C}$. Disks with azoxystrobin are not shown because no growth was observed at both discriminatory doses. Arrow indicates direction of growth from inner edge of disk. 
Table 4. Overall accuracy of four assays in evaluating fungicide sensitivity of Monilinia fructicola on fungicide-amended media 24 and 48 h after inoculation

\begin{tabular}{|c|c|c|c|c|c|c|c|c|}
\hline \multirow[b]{4}{*}{ Assay } & \multicolumn{8}{|c|}{ Correct observations $(\%)^{\mathrm{a}}$} \\
\hline & \multicolumn{4}{|c|}{ Propiconazole } & \multicolumn{4}{|c|}{ Thiophanate-methyl } \\
\hline & \multicolumn{2}{|c|}{$0.3 \mu \mathrm{g} / \mathrm{ml}$} & \multicolumn{2}{|c|}{$2.0 \mu \mathrm{g} / \mathrm{ml}$} & \multicolumn{2}{|c|}{$1.0 \mu \mathrm{g} / \mathrm{ml}$} & \multicolumn{2}{|c|}{$50.0 \mu \mathrm{g} / \mathrm{ml}$} \\
\hline & $24 \mathrm{~h}$ & $48 \mathrm{~h}$ & $24 \mathrm{~h}$ & $48 \mathrm{~h}$ & $24 \mathrm{~h}$ & $48 \mathrm{~h}$ & $24 \mathrm{~h}$ & $48 \mathrm{~h}$ \\
\hline Petri dish & $75.0 \pm 22.8$ & $87.7 \pm 12.3$ & 100 & 100 & $74.4 \pm 25.6$ & $87.5 \pm 10.0$ & $85.5 \pm 12.5$ & $87.5 \pm 12.5$ \\
\hline Lipbalm & $93.7 \pm 6.3$ & 100 & 100 & 100 & $89.5 \pm 10.5$ & $86.5 \pm 12.5$ & $85.3 \pm 13.2$ & $85.3 \pm 13.3$ \\
\hline Swab & $87.7 \pm 11.6$ & $63.2 \pm 17.4$ & $94.5 \pm 5.5$ & $86.5 \pm 13.3$ & $63.5 \pm 36.0$ & $68.5 \pm 28.5$ & $77.5 \pm 13.3$ & $74.5 \pm 11.4$ \\
\hline Tube & $75.0 \pm 22.8$ & $75.0 \pm 22.8$ & $75.0 \pm 22.8$ & $75.0 \pm 22.8$ & $50.5 \pm 40.5$ & $81.0 \pm 19.0$ & $63.3 \pm 21.2$ & $75.0 \pm 23.0$ \\
\hline
\end{tabular}

a Means $\pm 95 \%$ confidence intervals of 80 observations (five replicates and two experimental runs for each of eight isolates).

against the sporulating area. This inoculation technique should reduce the risk of contamination when the device is used in the field. Preliminary results indicate that, $72 \mathrm{~h}$ after inoculation of PDA disks, $M$. fructicola is easily distinguishable from the common fungal contaminants Alternaria spp., Rhizopus stolonifer, Penicillium spp., and Geotrichum candidum (data not shown).

Compared with the petri dish method, the lipbalm assay has the main advantages of being more portable, potentially allowing a faster assessment (after 24 rather than $48 \mathrm{~h}$ ), and requiring less growth media, fewer supplies, and reduced storage space for large numbers of samples. However, the technique may require further improvement before it is applicable for field use. For example, use of a Moniliniaselective medium $(7,22)$ may avoid contamination that could lead to misinterpretation of observations.

\section{ACKNOWLEDGMENTS}

Technical Contribution No. 5310 of the Clemson University Experiment Station. This material is based upon work supported by the United States Department of Agriculture (USDA)-CSREES, under project number SC-1000642. This research was funded in part by the USDA-CSREES S-RIPM grant no. 2006-34103-17007 and the Clemson University Integrated Pest Management grant program. We thank T. J. Michailides, University of California, Davis, for providing some of the isolates used in this study.

\section{LITERATURE CITED}

1. Anonymous. 1982. Recommended methods for the detection and measurement of resistance of agricultural pests to pesticides. FAO Plant Prot. Bull. 30:36-143.

2. Anonymous. 1991. FRAC methods for monitoring fungicide resistance. EPPO Bull. 21:291-354.

3. Avila-Adame, C., Olaya, G., and Köller, W. 2003. Characterization of Colletotrichum graminicola isolates resistant to strobilurinrelated QoI fungicides. Plant Dis. 87:14261432.

4. Brannen, P. M., Hotchkiss, M., Reilly, C., and Schnabel, G. 2006. Evaluation of fungicide programs to manage a DMI-resistant Monilinia fructicola population in a Georgia peach research block, 2005. Fungic. Nematicide Tests 61:STF001.

5. Brannen, P. M., and Schnabel, G. 2005. Brown rot. Pages 127-132 in: Southeastern Peach Growers' Handbook. D. Horton and D. Johnson, eds. Cooperative Extension Service, University of Georgia, Athens.

6. Cohen, J. 1994. The earth is round $(P<0.05)$. Am. Psychol. 49:997-1003

7. El-Ghaouth, A., Wilson, C. L., and Wisniewski, M. 1997. Antifungal activity of 2deoxy-D-glucose on Botrytis cinerea, Penicillium expansum, and Rhizopus stolonifer: ultrastructural and cytochemical aspects. Phytopathology 87:772-779.

8. Förster, H., Kanetis, L., and Adaskaveg, J. E. 2004. Spiral gradient dilution, a rapid method for determining growth responses and 50\% effective concentration values in fungusfungicide interactions. Phytopathology 94:163170.

9. Fraaije, B. A., Butters, J. A., Coelho, J. M., Jones D. R., and Hollomon. D. W. 2002. Following the dynamics of strobilurin resistance in Blumeria graminis f. sp. tritici using quantitative allele-specific real-time PCR measurements with the fluorescent dye SYBR green I. Plant Pathol. 51:45-54.

10. Gullino, M. L., Gilardi, G., Tinivella, F., and Garibaldi, A. 2004. Observations on the behaviour of different populations of Plasmopara viticola resistant to QoI fungicides in Italian vineyards. Phytopathol. Mediterr. 43:341-350.

11. Kim, Y. S., Dixon, E. W., Vincessi, P., and Farman, M. L. 2003. Field resistance to strobilurin (QoI) fungicides in Pyricularia griesea caused by mutations in the mitochondrial cytochrome $b$ gene. Phytopathology 93:891-900.

12. Köller, W., Parker, D. M., Turechek, W. W., and Avila-Adame, C. 2004. A two-phase resistance response of Venturia inaequalis populations to the QoI fungicides kresoxim-methyl and trifloxystrobin. Plant Dis. 88:537-544.

13. Lalancette, N., Jr., Russo, J. M., and Hickey, K. D. 1984. A simple device for sampling spores to monitor fungicide resistance in the field. Phytopathology 74:1423-1425.

14. Luck, J. E., and Gillings, M. R. 1995. Rapid identification of benomyl resistant strains of Botrytis cinerea using the polymerase chain reaction. Mycol. Res. 99:1483-1488.

15. Ma, H., and Michailides, T. J. 2005. Advances in understanding molecular mechanisms of fungicide resistance and molecular detection of resistant genotypes in phytopathogenic fungi.
Crop Prot. 24:853-863.

16. Ma, Z. H., Yoshimura, M. A., Holtz, B. A., and Michailides, T. J. 2005. Characterization and PCR-based detection of benzimidazoleresistant isolates of Monilinia laxa in California. Pest Manage. Sci. 61:449-457.

17. Ma, Z. H., Yoshimura, M. A., and Michailides, T. J. 2003. Identification and characterization of benzimidazole resistance in Monilinia fructicola from stone fruit orchards in California. Appl. Environ. Microbiol. 69:7145-7152.

18. Ogawa, J. M., and English, H. 1995. Brown rot. Pages 7-10 in: Compendium of Stone Fruit Diseases. J. M. Ogawa, E. I. Zehr, G. W. Bird, D. F. Ritchie, K. Uriu, and J. K. Uyemoto, eds. American Phytopathological Society, St. Paul, $\mathrm{MN}$.

19. Ogawa, J. M., Manji, B. T., Bostock, R. M., Canez Jr., V. M., and Bose, E. A. 1984. Detection and characterization of benomyl-resistant Monilinia laxa on apricots. Plant Dis. 68:2931.

20. Parker, D. M., Zhang, N., Smart, C. D., and Köller, W. D. 2006. Polymorphism of 14 alpha-demethylase gene (CYP51) in brown rot pathogen Monilinia fructicola from a resistant orchard in New York State. (Abstr.) Phytopathology 96:S90.

21. Pasche, J. S., Wharam, C. M., and Gudmestad, N. C. 2004. Shift in sensitivity of Alternaria solani to QoI fungicides. Plant Dis. 88:181187.

22. Phillips, D. J., and Harvey, J. M. 1975. Selective medium for detection of inoculum of Monilinia spp. on stone fruits. Phytopathology 65:1233-1236.

23. Schnabel, G., Bryson, P. K., Bridges, W. C., and Brannen, P. M. 2004. Reduced sensitivity in Monilinia fructicola to propiconazole in Georgia and implications for disease management. Plant Dis. 88:1000-1004.

24. Schnabel, G., Dai, Q., and Paradkar, M. R. 2003. Cloning and expression analysis of the ATP binding cassette transporter $M F A B C 1$ gene and the alternative oxidase gene MAAOXI from Monilinia fructicola. Pest Manage. Sci. 59:1143-1151.

25. Shamoun, S. F., and Sieber, T. N. 1993 Isozyme and protein-patterns of endophytic and disease syndrome-associated isolates of Melanconium apiocarpum and Melanconium marginale collected from alder. Mycotaxon 49:151-166.

26. Zehr, E. I., Toler, J. E., and Luszcz, L. A. 1991. Spread and persistence of benomyl-resistant Monilinia fructicola in South Carolina peach orchards. Plant Dis. 75:590-593. 